\title{
Dermatological disorders during pregnancy: a study from tertiary care hospital
}

\author{
Krina B. Patel*, Ruchin Patel, Nisha Sharma
}

Department of Dermatology, GMERS Medical College, Sola, Ahmedabad

Received: 12 March 2016

Accepted: 05 April 2016

\author{
*Correspondence: \\ Dr. Krina B. Patel, \\ E-mail: y2k_kbpatel@yahoo.com
}

Copyright: (c) the author(s), publisher and licensee Medip Academy. This is an open-access article distributed under the terms of the Creative Commons Attribution Non-Commercial License, which permits unrestricted non-commercial use, distribution, and reproduction in any medium, provided the original work is properly cited.

\begin{abstract}
Background: Various types of physiological and pathological mucocutaneous changes are commonly observed during pregnancy. Infectious, non-infectious and pregnancy specific dermatoses are seen during pregnancy. This study was carried out with an aim of studying association of various dermatosis with pregnancy and to find out incidence of pregnancy specific dermatoses v/s non-specific dermatosis.

Methods: Total 131 pregnant female presenting with complain of skin lesions were included in study. Detail examination and necessary investigations were carried out to diagnose type of skin disease.

Results: Out of 131 patients, only $11(8.4 \%)$ patients presented with pregnancy specific dermatoses while rest 120 $(91.6 \%)$ presented with pregnancy non-specific dermatoses. Among pregnancy non-specific dermatoses, noninfectious conditions were found in $48.1 \%$ and $43.5 \%$ presented with infectious dermatoses. Most common infectious dermatoses was herpes labialis while most common non-infectious dermatosis was pruritus.

Conclusions: Pregnancy specific dermatoses are rare and require vigilant eye to recognize them while wide variety of pregnancy non-specific dermatoses are commonly encountered and require prompt diagnosis and treatment for uneventful pregnancy outcome.
\end{abstract}

Keywords: Pregnancy dermatoses, Pregnancy specific and non-specific dermatoses

\section{INTRODUCTION}

Various phases in human life are associated with various changes in the human body, skin changes are one which are most obvious. Pregnancy, a reproductive process in woman's life is associated with profound metabolic and hormonal changes which lead to alteration in pigmentation, vascular system, hair, nail etc. Both physiological and pathological mucocutaneous changes are commonly observed during pregnancy. ${ }^{1,2}$

Profound physiological changes in pregnancy lead to various skin changes like pigmentation, connective tissue changes like striae, vascular changes like varicosities, gingival hyperplasia, hemorrhoids, spider angiomas, palmar erythema etc., altered glandular functions leading to hyperhidrosis, dyshidrotic eczema, seborrhea, changes in hair and nail etc. The pre-existing skin conditions may improve, alter or exacerbate during pregnancy like acne, psoriasis, several types of nevi etc. due to immunological, endocrinological, metabolic and vascular changes in pregnancy. ${ }^{3}$ The severity and frequency of infective skin conditions like candidial vulvo-vaginitis, bacterial vaginosis, trichomonal vaginitis, dermatophyte infection, genital warts, pityrosporum folliculitis, herpes zoster and herpes simplex are increased in pregnancy due to decreased cell mediated immunity during pregnancy. Sexually transmitted infections during pregnancy can have catastrophic effect on health of mother and fetus. Leprosy and tuberculosis also may have untoward effect on both pregnancy and fetus. Auto-immune connective tissue diseases like SLE, SS, DM and other noninfectious conditions like melanoma, neurofibromatosis, atopic dermatitis etc may improve or worsen during pregnancy. Pregnancy specific dermatoses represent a heterogenous group of disorders which occur exclusively during pregnancy and child birth. Though specific to pregnancy they have varied morphology and may mimic 
other skin disorders so diagnosis is difficult and management is equally difficult considering safety of inutero life. Classification of pregnancy specific dermatoses has been revised based on recent studies. ${ }^{4}$

Pemphigoid gestationis, polymorhphic eruption of pregnancy or pruritic urticarial papules and plaques of pregnancy (PUPPP), intrahepatic cholestasis of pregnancy, pustular psoriasis of prgenancy and atopic eruption of pregnancy are now considered as pregnancy specific dermatoses. This classification combines several different entities of past like prurigo of pregnancy and pruritic folliculitis of pregnancy is classified as atopic eruption of pregnancy now.

All above types of skin diseases pose a great therapeutic challenge during pregnancy and some of them may have unfavorable outcome on pregnancy and newborn. So identifying them and studying their course is important aspect of management of pregnancy.

So this study was carried out with an aim of studying association of various dermatosis with pregnancy and to find out incidence of pregnancy specific dermatoses v/s non-specific dermatosis.

\section{METHODS}

A cross-sectional study was carried out on 131 pregnant female patients presenting in dermatological OPD of a teaching institute between study period of 2012 to 2014 with complain of skin and/or mucosal lesions. Detailed history and clinical examination were done in each patient as per pre-defined Proforma. Detailed history included demographic data, complains related to skin/mucosa, presence of itching or other symptoms, onset of disease in relation to pregnancy, history of other medical diseases including jaundice, any past skin disorder, family history of similar or other skin disorders, presence or absence of similar skin lesions in previous pregnancy if any were recorded. Thorough physical examination of patient was carried out with emphasis on skin and/or mucosal lesions. Complete blood count, Liver and renal function tests, S. VDRL and S. HIV tests were obtained for all patients. Skin biopsy, Gram stain, $\mathrm{KOH}$ preparation, wet mount, vaginal $\mathrm{PH}$ test, Tzanck smear were done as and when indicated. USG and X-ray were advised only if necessary.

\section{RESULTS}

A total of 131 pregnant female patients were included in the study from 2012 to 2014 . Out of 131 patients, 60 were primi gravida and 71 were multi gravida. Most common age group seen in our study was $21-30$ years $(\mathrm{n}=88,67.2 \%)$ (Table 1$)$ Mean age of the patients was 24.87 years.

Table 1: Age group of patients.

\begin{tabular}{|ll|}
\hline Age group & No. of patients $(\%)$ \\
\hline$<20$ years & $17(12.97)$ \\
\hline $21-30$ years & $88(67.17)$ \\
\hline $31-40$ years & $26(19.84)$ \\
\hline$>40$ years & $0(0)$ \\
\hline Total & $131(100)$ \\
\hline
\end{tabular}

Table 2: Specific dermatoses of pregnancy as per trimester.

\begin{tabular}{|llllll|}
\hline Disease & $1^{\text {st }}$ trimester & $2^{\text {nd }}$ trimester & $3^{\text {rd }}$ trimester & Total & $\%$ from study population \\
\hline PUPPP & 0 & 1 & 4 & 5 & 3.81 \\
\hline ICP & 0 & 0 & 3 & 3 & 2.29 \\
\hline Pustular psoriasis & 0 & 0 & 1 & 1 & 0.76 \\
\hline AEP & 0 & 1 & 1 & 2 & 1.52 \\
\hline Total & 0 & 2 & 9 & 11 & 8.38 \\
\hline
\end{tabular}

Out of 131 patients; $11(8.4 \%)$ presented with specific dermatoses of pregnancy. Specific dermatoses seen were Atopic eruption of pregnancy (AEP), Pruritic urticarial papules and plaques of pregnancy (PUPPP), intrahepatic cholestasis of pregnancy (ICP), Pustular psoriasis of pregnancy. (Figure 1,2) Analysis of these patients with relation to pregnancy stage and type of pregnancy are presented in Table $2 \& 3.8$ patients with pregnancy specific dermatoses were primigravida. Out of 3 multigravida, only one patient with PUPPP had past history of similar skin lesions in previous pregnancy.
63 patients $(48.1 \%)$ presented with non-infectious dermatoses including physiological changes of pregnancy (Table 4) (Figure 3, 4) and 57 patients $(43.5 \%)$ presented with infectious dermatoses (Figure 5), Sexually transmitted infections (STIs) of various types were found in $34(59.6 \%)$ patients among infectious diseases (Table 5) (Figure 6) and 23 (40.4\%) patients presented with other infectious conditions (Table 6). Out of 131 patients; 4 were found to be HIV reactive and 7 patients had RPR tests positive in titer more than 1:16 which were confirmed by S. TPHA tests in all the patients. Two patients among these had skin lesions of secondary 
syphilis. None other were found to have active lesions of syphilis in them or their partners at the time of presentation.

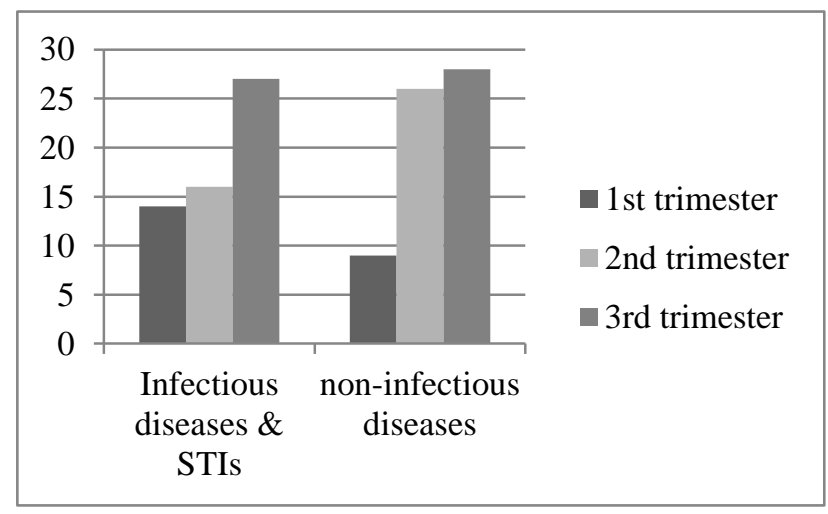

Figure 1: Infectious and non-infectious conditions according to pregnancy.

Among non-infectious skin conditions pruritus top the chart, followed by patients presenting for physiological changes of pregnancy. Wide variety of other dermatoses were encountered including acne and acneiform eruptions, urticaria and drug reactions, acanthosis nigricans, atopic dermatitis etc. All Neurofibromatosis patients presented in $1^{\text {st }}$ trimester; due to vigilant gynecologists referring patients early. All patients were counseled regarding possible effects of pregnancy on their skin lesions, genetic nature of condition and probability of transfer of disease in their babies. Pemphigus vulgaris worsening in 2 nd trimester was seen in one patient with clinical features resembling Pemphigoid Gestationis, diagnosis of pemphigus was confirmed by biopsy and immunofluoroscence study. One patient presented with significant edema of vulva due to intra-abdominal pressure leading to lymphatic obstruction at inguinal area.

Table 3: Pregnancy specific dermatosis according to gravida

\begin{tabular}{|lll|}
\hline Disease & Primigravida & Multigravida \\
\hline PUPPP & 4 & 1 \\
\hline ICP & 1 & 2 \\
\hline Pustular psoriasis & 1 & 0 \\
\hline AEP & 2 & 0 \\
\hline Total & 8 & 3 \\
\hline
\end{tabular}

Table 4: Non-infectious dermatoses according to trimester.

\begin{tabular}{|c|c|c|c|c|c|}
\hline Disease & $\mathbf{1}^{\text {st }}$ trimester & $2^{\text {nd }}$ trimester & $3^{\text {rd }}$ trimester & $\begin{array}{l}\text { No. of } \\
\text { patients }\end{array}$ & $\begin{array}{l}\% \text { of study } \\
\text { population }\end{array}$ \\
\hline Acne and Acneiform eruption & 2 & 1 & 1 & 4 & 3.05 \\
\hline Atopic dermatitis & 0 & 0 & 1 & 1 & 0.76 \\
\hline $\begin{array}{l}\text { Nummular Eczema/ perioral } \\
\text { dermatitis }\end{array}$ & 0 & 3 & 1 & 4 & 3.05 \\
\hline Pruritus with or without xerosis & 0 & 6 & 5 & 11 & 8.38 \\
\hline Fox-Fordyce disease & 0 & 1 & 0 & 1 & 0.76 \\
\hline Acanthosis nigricans & 0 & 0 & 3 & 3 & 2.29 \\
\hline Neurofibromatosis & 3 & 0 & 0 & 3 & 2.29 \\
\hline Psoriaisis & 1 & 0 & 0 & 1 & 0.76 \\
\hline Lichen planus & 0 & 1 & 0 & 1 & 0.76 \\
\hline Other papulo-squamous disorders & 0 & 3 & 1 & 4 & 3.05 \\
\hline $\begin{array}{l}\text { Vesiculo-bullous eruptions } \\
\text { (Pemphigus vulgaris) }\end{array}$ & 0 & 1 & 0 & 1 & 0.76 \\
\hline Urticaria and Drug reactions & 3 & 2 & 1 & 6 & 4.58 \\
\hline Vitiligo & 0 & 1 & 0 & 1 & 0.76 \\
\hline $\begin{array}{l}\text { Oral mucosal lesions including } \\
\text { apthae }\end{array}$ & 0 & 1 & 2 & 3 & 2.29 \\
\hline Genital lymphedema & 0 & 0 & 1 & 1 & 0.76 \\
\hline Nevi & 0 & 0 & 3 & 3 & 2.29 \\
\hline $\begin{array}{l}\text { Physiological changes including } \\
\text { striae, linea alba, pigmentation }\end{array}$ & 0 & 6 & 9 & 15 & 11.45 \\
\hline Total & 9 & 26 & 28 & 63 & 48.09 \\
\hline
\end{tabular}

\section{DISCUSSION}

Various types of skin lesions are encountered in pregnancy including physiological changes in pregnant women due to profound endocrinological changes, various infectious and non-infectious skin lesions due to altered immune status in pregnancy and pregnancy specific dermatoses. 
In our study; we included 131 pregnant female patients coming to dermatological OPD for treatment of skin changes observed by themselves or referred by gynecologist. The most common presenting age group in our study was 21-30 years of age with slightly higher number of multigravida $(54.2 \%)$. Various other studies by Raj $\mathrm{S}$ et al, Kumari R et al etc reported 16-30 years as common age group in their studies. ${ }^{5,6}$ Shivkumar V et al reported 11 -20 years as common age group in their study. ${ }^{7}$ Similar incidence of multigravida and primigravida has been reported in these various studies.

Table 5: Infectious skin disorders excluding STIs.

\begin{tabular}{|ll|llll|}
\hline Skin condition & $1^{\text {st }}$ trimester & $2^{\text {nd }}$ trimester & $3^{\text {rd }}$ trimester & No. of patients & \% from study population \\
\hline Herpes labialis & 0 & 4 & 2 & 6 & 4.58 \\
\hline Chicken - Pox & 0 & 1 & 0 & 1 & 0.76 \\
\hline Dermatophyte infection & 0 & 2 & 1 & 3 & 2.29 \\
\hline Tinea versicolor & 1 & 1 & 0 & 2 & 1.52 \\
\hline Bacterial infection of skin & 0 & 1 & 3 & 4 & 3.05 \\
\hline Scabies/pediculosis & 2 & 0 & 0 & 2 & 1.52 \\
\hline Leprosy without reaction & 1 & 0 & 0 & 1 & 0.76 \\
\hline Leprosy with Lepra reaction & 0 & 0 & 1 & 1 & 0.76 \\
\hline Viral warts - extragenital & 0 & 0 & 3 & 3 & 2.29 \\
\hline Total & 4 & 9 & 10 & 23 & 17.55 \\
\hline
\end{tabular}

Table 6: Analysis of patients with STIs.

\begin{tabular}{|lllll|}
\hline Disorder & $1^{\text {st }}$ trimester & $2^{\text {nd }}$ trimester & $3^{\text {rd }}$ trimester & No. of patients $(\%)$ \\
\hline Herpes Genitalis & 0 & 0 & 5 & $5(3.81)$ \\
\hline Genital warts & 0 & 1 & 4 & $5(3.81)$ \\
\hline Bacterial vaginosis & 0 & 0 & 2 & $2(1.52)$ \\
\hline T. vaginalis & 1 & 0 & 0 & $1(0.76)$ \\
\hline Genital molluscum & 0 & 2 & 1 & $3(2.29)$ \\
\hline Vulvo-vaginal candidiasis & 6 & 3 & 5 & $14(10.68)$ \\
\hline Chancroid & 1 & 0 & 0 & $1(0.76)$ \\
\hline Mix STI & 1 & 0 & 0 & $1(0.76)$ \\
\hline Syphilis & 1 & 1 & 0 & $2(1.52)$ \\
\hline Total & 10 & 7 & 17 & $34(25.95)$ \\
\hline
\end{tabular}

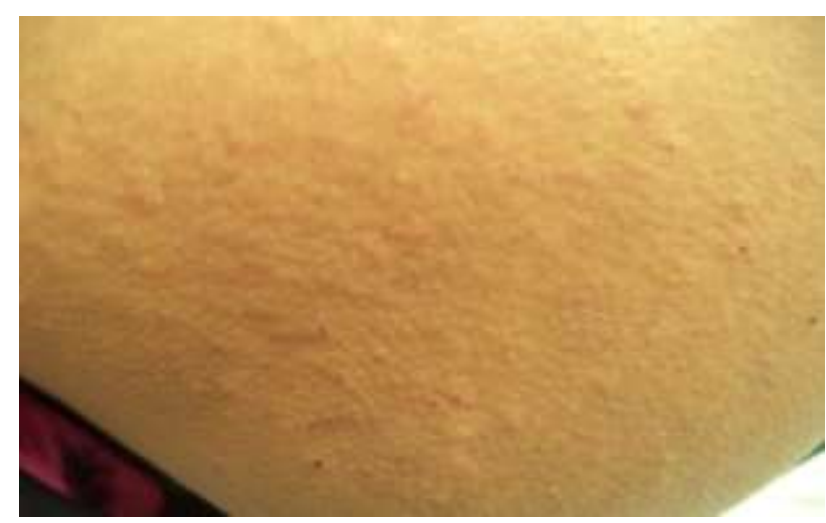

Figure 2: Pruritic urticarial papules and plaques of pregnancy.

Pruritus without identifiable cause except xerosis in few patients was the most common dermatoses $(n=11,8.4 \%)$ in our study. Various studies have reported $18 \%$ to $54 \%$ incidence of pruritus due to various causes. ${ }^{7-9}$

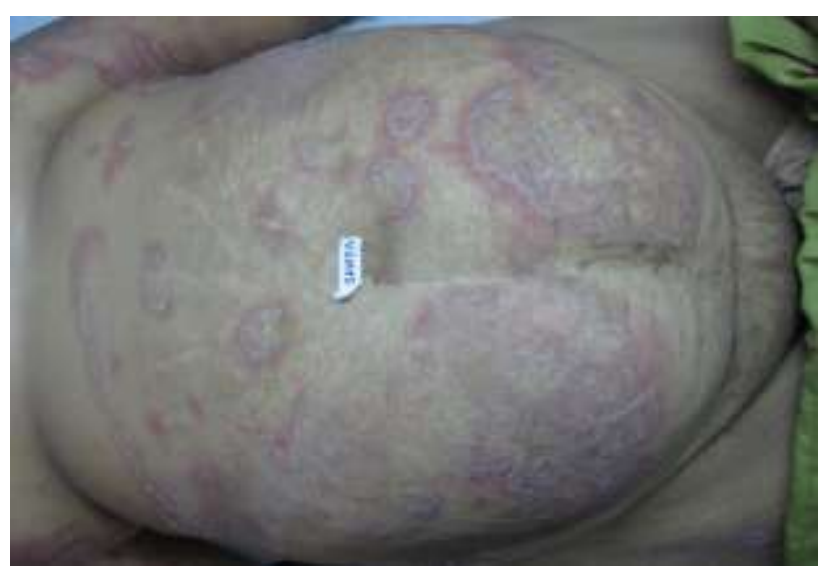

Figure 3: Pustular psoriasis of pregnancy. 


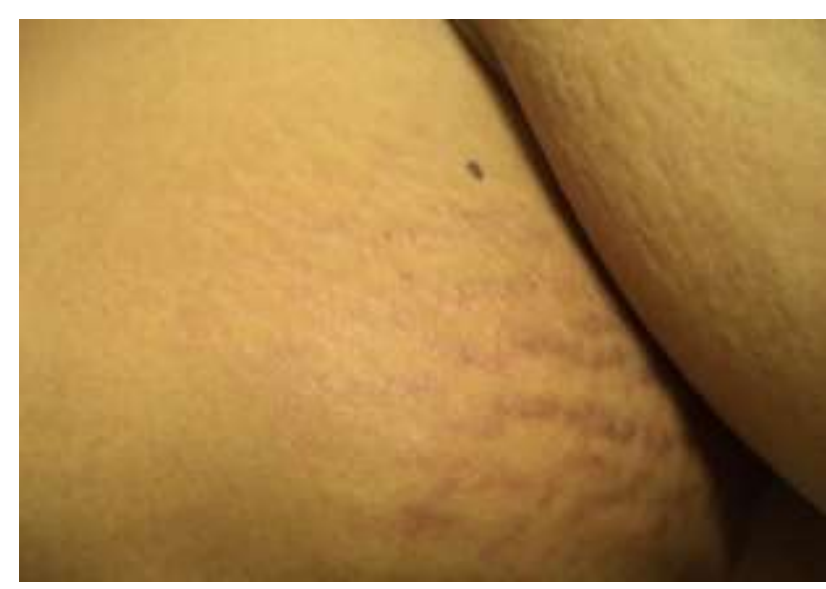

Figure 4: Pregnancy striae.

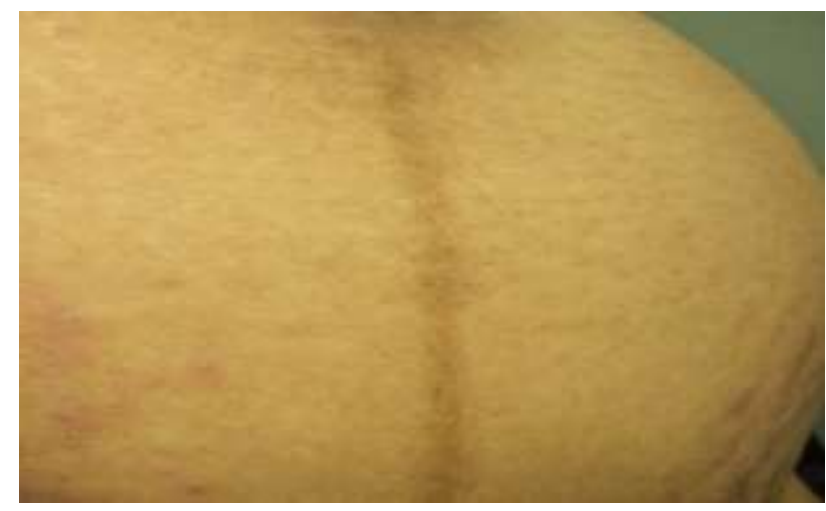

Figure 5: Linea alba.

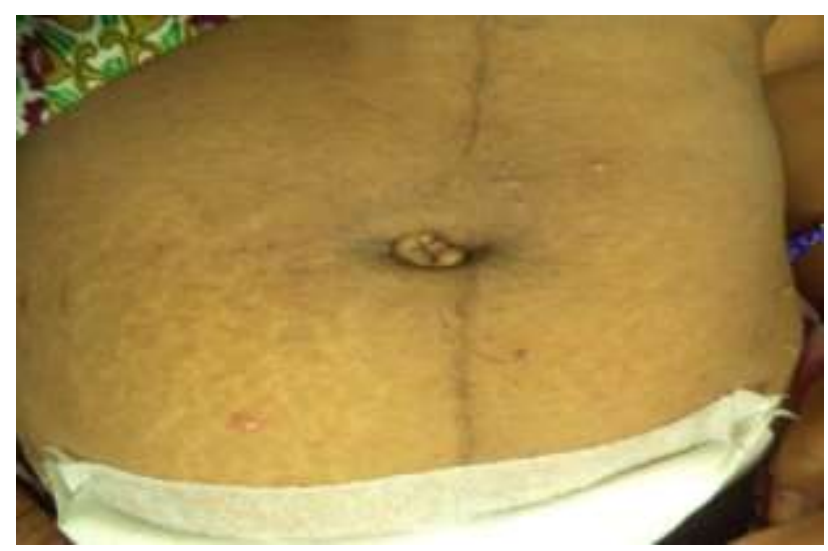

Figure 6: Chicken Pox in pregnancy.

Among the specific dermatosis of pregnancy prurigo of pregnancy has been reported to be most common by Shivkumar et al, Raj et al $(9.41 \%, 12.28 \%)$, while Kumari et al reported only $0.68 \%$ incidence. We encountered 2 cases (1.5\%) of Prurigo of pregnancy which is now classified as $\mathrm{P}$ Type atopic eruption of pregnancy. ${ }^{5-7}$ PUPPP was found more frequently in our study $(3.8 \%)$. Out of 11 patients with pregnancy specific dermatosis; nine presented in $3^{\text {rd }}$ trimester $(81.8 \%)$.

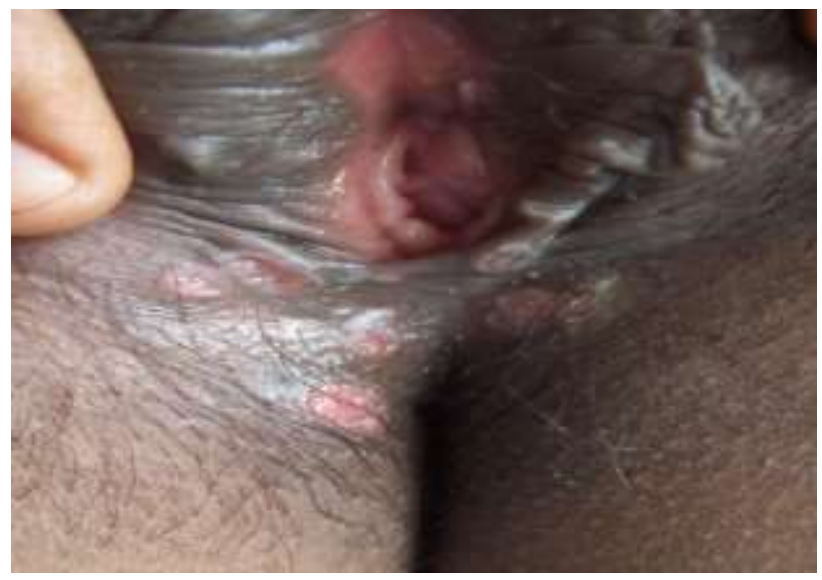

Figure 7: Ulcerative STI (Mix STI) in pregnant female.

We found Vulvo-vaginal candidiasis ( $10.68 \%$ ) as most common STI in study population Similar results were obtained in study by Kumari et al $(11.56 \%) .{ }^{6}$ While Raj et al $(39.47 \%)$ and Shivkumar et al $(21.78 \%)$ found higher incidence of VVC in their studies. ${ }^{5,7}$

Most of the patients in infectious and non-infectious group presented in $2^{\text {nd }}$ or $3^{\text {rd }}$ trimester while patients with pre-existing skin conditions like psoriasis, neurofibromatosis presented in $1^{\text {st }}$ trimester. Chart 1 shows distribution of patients in relation to pregnancy duration.

The study highlights wide variety of skin disorders seen during pregnancy including pregnancy specific and nonspecific disorders. Development of physiological changes during pregnancy can also lead to mental stress in pregnant woman of today who is more and more concern about cosmetic outcomes.

This study also emphasizes importance of recognizing and treating dermatological disorders in pregnancy specifically various infectious conditions and sexually transmitted diseases which can have detrimental outcome for unborn baby.

We found most of the patients presenting in 21-30 years of age. Though pregnancy specific dermatoses were less frequently encountered in our study with only $8.4 \%$ incidence, PUPPP was the most common dermatoses among them. We did not come across any case of Pemphigoid gestationis. Pruritus was the most common non-infectious condition seen which required thorough investigations to find out cause for the same. VVC was the most common STI seen in our study; though we found all types of STI in pregnant females which was alarming. Herpes labialis due to probable altered hormonal status was most common among infectious diseases seen. Genital warts were most difficult to manage due to same reason. 
Funding: Not required

Conflict of interest: None declared

Ethical approval: The study was approved by the Institutional Ethics Committee

\section{REFERENCES}

1. Karen JK, Pomeranz MK. Skin changes and diseases in pregnancy. In: Goldsmith L A, editor. Fitzpatrick's dermatology in general medicine. 8th ed. USA: The McGraw-Hill Companies, Inc; 2012.pp. 1204-12.

2. Kroumpouzos G, Cohen LM. Dermatoses of pregnancy. J Am Acad Dermatol. 2001;45:1-19.

3. Ambros-Rudolph CM. Disorders of pregnancy. In Burgdorf WHC, Plewig G, Wolff HH, Landthaler M, editors. Braun-Falco's dermatology. 3rd ed. Heidelberg: Springer Medizin Veralg: 2009.pp 11601169.

4. Ambros-Rudolph CM, Mullegger RR, VaughenJones SA, Kerl H, Black MM. The specific dermatoses of pregnancy revisited and reclassified: resuls of a retrospective two-center study on 505 pregnant patients. J Am Acad Dermatol. 2006;54:395-404.

5. Raj S, Khopkar U, Kapasi A, Wadhwa SL. Skin in pregnancy. Indian J Dermatol Venereol Leprol. 1992;58:84-8.

6. Kumari R, Jaisankar TJ, Thappa DM. A clinical study of skin changes in pregnancy. Indian $\mathrm{J}$ Dermatol Venereol Leprol. 2007;73:141.

7. Shivakumar V, Madhavamurthy P. Skin in pregnancy. Indian J Dermatol Venereol Leprol. 1999;65:23-5.

8. Wong RC, Ellis CN. Physiologic skin changes in pregnancy. J Am Acad Dermatol. 1984;10:929-40.

9. Roger D, Vaillant L, Fognon A. Specific pruritic diseases of pregnancy. Arch Dermatol 1994;130:7349.

Cite this article as: Patel KB, Patel R, Sharma N. Dermatological disorders during pregnancy: a study from tertiary care hospital. Int J Reprod Contracept Obstet Gynecol 2016;5:1354-9. 